\title{
Argumentação, humor e incongruência na linguagem da criança
}

DOI: http://dx.doi.org/10.21165/el.v48i2.2360

\section{Alessandra Jacqueline Vieira' \\ Alessandra Del Ré ${ }^{2}$}

\section{Resumo}

Este artigo tem por objetivo discutir a questão da incongruência nos discursos humorístico e argumentativo, tratando da definição de cada um desses termos e, além disso, de sua emergência na fala das crianças. Para tanto, trazemos, para embasar as discussões, alguns dados produzidos por duas crianças brasileiras monolíngues - português, G. e S., gravadas em situação de interação com os pais e nos contextos cotidianos, como o jantar, durante suas brincadeiras, entre outros. Trata-se de investigar de que modo a argumentação e o humor estão relacionados na fala dessas crianças, interligadas muitas vezes pela incongruência, fenômenos ainda pouco estudados nas pesquisas sobre a aquisição de linguagem, especialmente sobre as intersecções desses elementos na fala de crianças pequenas. Nossas primeiras observações demonstram que as crianças utilizam precocemente estratégias linguísticas, tanto para defender seu ponto de vista quanto para escapar da repreensão de seus pais e, muitas vezes, elas as fazem utilizando o humor.

Palavras-chave: argumentação; humor; incongruência; criança; linguagem na infância.

\footnotetext{
1 Universidade Federal do Rio Grande do Sul (UFRGS), Porto Alegre, Rio Grande do Sul, Brasil; alessandra.vieira@ufrgs.br; https://orcid.org/0000-0002-3216-6107

2 Universidade Estadual Paulista (UNESP), Araraquara, São Paulo, Brasil; aledelre@fclar.unesp.br; https://orcid.org/0000-0002-6740-9631
} 


\title{
Argumentation, humor and incongruence in the child's speech.
}

\begin{abstract}
This article aims to discuss the issue of incongruity in humorous and argumentative discourses, dealing with the definition of each of these terms and, besides that, of their emergence in children's speech. For this, we bring some data produced by two Brazilian monolingual children - Portuguese, G. and S., recorded in situations of interaction with parents and in natural contexts, such as dinner, during their play, among others. It is a question of investigating how arguments and humor are related in the speech of these children, often interconnected by incongruity, phenomena that are still little studied in the process of language acquisition, especially about the intersections of these elements in the speech of young children. Our first observations demonstrate that children use early language strategies to defend their point of view and to escape the reproof of their parents and often they do that using humor.
\end{abstract}

Keywords: Argumentation; Humor; Incongruity; Child, Childhood language.

\section{Introdução}

Este texto tem por objetivo discutir aspectos da incongruência nos discursos humorístico e argumentativo, produzidos por duas crianças brasileiras monolíngues - português, G. e S., falantes do Português do Brasil (PB), gravadas em situação de interação com os pais e nos contextos cotidianos, como o jantar, durante suas brincadeiras, entre outros. Tratase de investigar de que modo a argumentação e o humor estão relacionados na fala dessas crianças, interligadas muitas vezes pela incongruência, uma ruptura na cadeia dialógica, como explicaremos melhor adiante. Vale dizer que o humor e a argumentação, enquanto objetos de estudo na fala da criança, inserem-se em projetos mais amplos, no Brasil $^{3}$ e na França ${ }^{4}$, e já foram tema de outras publicações.

3 Projetos: O humor na infância: um olhar dialógico-discursivo para os dados de fala de crianças brasileiras - PQ/CNPq; Argumentação e explicação: modos de construção/constituição do conhecimento (Grupo ANPEPP).

40 projeto RIHA, Rire, Humour et Acquisition du langage Coordenado pela Prof. Dr. Aliyah Morgenstern, docente na Universidade Sorbonne Nouvelle - Paris 3, na França, e pela Profa. Dra. Alessandra Del Ré, docente da Universidade Estadual Paulista-Araraquara, no Brasil. Site: http://enflang.ortolang.fr/humour/accueil.html. O grupo NALingua é composto por pesquisadores vinculados a diferentes Instituições de Ensino Superior do Brasil (UNESP, USP, UNICAMP, UFPB, UFPE, UFAL, UFRGS, dentre outras) e da França (Université de Montpellier 3). Site: http://gruponalingua.com.br/apresentacao.html . 
Em estudos anteriores (VIEIRA, 2011; VIEIRA, 2015;VIEIRA; LEITÃO, 2014, LEITÃO; VIEIRA, 2017; DEL RÉ, 2011; DEL RÉ, 2003; DEL RÉ, MORGENSTERN, DODANE, 2015), trabalhamos com os elementos aqui elencados, como a questão da argumentação e da explicação no discurso infantil - tratando da importância desses elementos para o desenvolvimento da linguagem da criança, de seu funcionamento e de suas primeiras aparições nos dados e, também, dos aspectos do humor na fala da criança, especialmente sobre a produção de discursos humorísticos. Em um desses trabalhos (especificamente o de Vieira, 2015)5, refletimos sobre os diferentes estudiosos que, histórica e contemporaneamente, trataram dos termos (argumentação e explicação) e aprofundamos nosso conhecimento no que diz respeito ao discurso argumentativo na criança. Naquela pesquisa, durante as análises, verificamos uma importante relação entre a argumentação e o humor, especialmente quando certas incongruências na produção de um enunciado argumentativo iniciavam uma ruptura que causava o riso no interlocutor e/ou no próprio locutor.

A questão do humor vem sendo desenvolvida desde 2003 (DEL RÉ, 2011) e as discussões que traremos aqui dão continuidade a reflexões feitas também em parceria, no Brasil e na França, sobretudo a partir do projeto RIHA (DEL RÉ et al., 2015, 2017 etc.).

Nossos estudos, em ambos os temas, partem de uma perspectiva dialógico-discursiva, com base em estudos de Bakhtin e do Círculo (BAKHTIN, 1997, BAKHTIN/VOLOSHINOV, 1995; SALAZAR-ORVIG, 1999; FRANÇOIS, 1994, 2009), que consideram, de um lado, que o sujeito se constitui em seu discurso, por meio do encadeamento dos enunciados e dos movimentos de sentido trazidos por esses encadeamentos, e, por outro lado, que esse sujeito pode ser "recuperado" por meio de uma construção do intérprete/receptor (FRANÇOIS, 1994). Tal abordagem vem sendo desenvolvida no Brasil pelo grupo GEALin/ NALingua (CNPq), resultando em publicações, dentre elas dois livros relacionados à Aquisição da Linguagem a partir de um olhar bakhtiniano (DEL RÉ et al., 2014a e 2014b).

O que propomos para este artigo é identificar em quais contextos um cruzamento entre argumentação e humor pode ser observado na fala da criança, uma vez que estes fenômenos podem revelar peculiaridades da aquisição de linguagem e, além disso, auxiliar a reflexão sobre a aquisição e o desenvolvimento da linguagem. Essa intersecção pode ser observada, acreditamos, a partir de uma ruptura no discurso (incongruência), que ora gera discursos mais argumentativos ora humorísticos ou ambos. Voltaremos adiante a essa questão.

Para observar essas questões, traremos dados de duas crianças brasileiras, com idade entre 24 e 48 meses de idade, um menino (G.) e uma menina (S.), pertencentes ao corpus

5 Orientado por Alessandra Del Ré no Brasil e desenvolvido em parte na Université Sorbonne Nouvelle Paris 3, sob orientação da profa. Aliyah Morgenstern, financiado pela CAPES/Bolsa PDSE e com realização entre setembro de 2012 e agosto de 2013. 
NALingua (DEL RÉ et al., 2016). Trata-se de dados coletados em contexto natural e em ambiente familiar. Ambas as crianças são monolíngues, falantes do português do Brasil. Foi a partir desses dados que refletimos sobre os aspectos da ruptura (incongruência), sendo alguns fragmentos instigantes para pensarmos a argumentação e o humor a partir desse elemento (ruptura) na fala da criança.

Os dados foram transcritos a partir do uso da ferramenta CLAN ${ }^{6}$ - cujas normas foram traduzidas para o português (DEL RÉ; HILÁRIO; MOGNO, 2014) -, disponível gratuitamente no site CHILDES.

\section{Argumentação na fala da criança}

A argumentação - assim como o humor -, enquanto fenômeno de linguagem que tem um papel fundamental no desenvolvimento e na aquisição de conhecimento pela criança, é analisada nesta pesquisa a partir de um viés que vai ao encontro de nossa perspectiva dialógico-discursiva, e tem base em discussões de Leitão (2000, 2001, 2007a, 2007b, 2008a, 2008b), para quem a argumentação é "uma atividade discursiva que se caracteriza pela defesa de ponto de vista e leva em consideração perspectivas contrárias" (LEITÃO, 2007a, p. 57), atividade que, acreditamos, contribui efetivamente para o desenvolvimento e a transformação do conhecimento.

Afastando-se, dessa forma, das noções que enquadram a argumentação em um modelo dissertativo ou mesmo em um método de ensino-aprendizagem, no qual os alunos nem sempre participam ativamente, Leitão (2007a) desenvolve uma teoria que abarca a participação ativa dos estudantes para a construção de uma argumentação. Para tanto, a autora trabalha com a importância do contraponto, da oposição de ideias entre interactantes, que contribui para a transformação e a reflexão dos próprios argumentos (e, consequentemente, do conhecimento). Sendo assim, para a autora, a argumentação é uma ferramenta essencial que pode ser utilizada para auxiliar no processo de aquisição/ aprendizagem de conhecimentos, como, por exemplo, nas escolas, e deve ser analisada a partir de três elementos (a saber: o argumento, o contra-argumento e a resposta) que constituem uma unidade de análise efetiva - considerada por ela sob três pontos de vista (discursivo, psicológico e epistêmico). Sendo assim, partindo do ponto de vista discursivo, a autora trata das questões que envolvem a presença do outro e a configuração desses três elementos em interação, partindo de noções propostas por Bakhtin (1997, 1995, 1976), no que concerne às questões de linguagem, alteridade, gênero etc. Em suas palavras,

6 Clan: http://alpha.talkbank.org/clan/ . Childes: https://childes.talkbank.org/ 
[O argumento:] consiste no conjunto de ponto de vista e justificativa, podendo um ou outro permanecer implícito nas argumentações cotidianas efetivamente produzidas. 0 argumento identifica o ponto de vista que seu proponente procura estabelecer, bem como as razões com as quais apoia (função discursiva). [...] [0 contra-argumento:] do ponto de vista discursivo, a presença do contra-argumento traz para o discurso uma dimensão de alteridade indispensável à ocorrência da argumentação. [Resposta:] A comparação entre formulação inicial do argumento e a retomada deste, em resposta a contraargumentos, é o recurso analítico que permite capturar eventuais mudanças nas posições inicialmente defendidas. Sua presença captura o estatuto fundamentalmente dialógico da unidade de análise postulada. (LEITÃO, 2007a, p. 84).

Além desses níveis, a autora defende que a argumentação comporta em si uma dinâmica dialética e dialógica. Ou seja, há em sua estrutura a consideração do outro, dos outros discursos, da situação de enunciação, do contexto (social, histórico etc.), que não envolve apenas dois indivíduos face a face, o que fornece uma dinâmica dialógica à argumentação. Ao mesmo tempo, por envolver o confronto, a oposição de ideias (e não de pessoas, simplesmente), a argumentação possui uma característica dialética.

Neste artigo, enfatizamos a importância do contra-argumento, pois acreditamos que ele seja um ponto importante a ser aprofundado, uma vez que é nesse momento que a incongruência parece surgir no enunciado, como uma ruptura no discurso, uma oposição ao argumento trazido à tona por um dos interlocutores. Observa-se, portanto, que, assim como para o humor, há incongruências que podem desencadear a argumentação ou ambos. Sendo assim, buscaremos verificar em que momento a incongruência gera um embate, o riso ou quando ela desencadeia os dois elementos ao mesmo tempo.

A opção por tratar da oposição explícita no discurso justifica-se, desse modo, pelo fato de podermos verificar, durante o surgimento desse tipo de argumentação, a revisão de um ponto de vista inicial do interlocutor ou o uso de estratégias argumentativas para convencer o outro de seu intuito ou ideia. Esse fenômeno pode ser verificado desde a infância, nos momentos em que a criança pede, solicita ou nega alguma coisa, ou, ainda, quando ela se opõe ao que o outro afirma etc. Trazemos um exemplo para ilustrar essas questões (VIEIRA; LEITÃO, 2014):

$$
\begin{aligned}
& \text { (33 meses - 2;9) Episódio 'Cócegas' } \\
& 2217{ }^{*} \mathrm{CHI}: 0 \text { [=! ri]. } \\
& \begin{array}{l}
2218{ }^{*} \mathrm{MOT}: \quad \text { o(lha) o que te espera aqui se (vo)cê vie(r) me } \\
\text { perturba }(r)
\end{array}
\end{aligned}
$$


2219 o(lha).

2220 \%act: MOT mostra o dedo indicador para a criança, como sinal de que irá fazer cócegas em $\mathrm{CHI}$.

$2221{ }^{*} \mathrm{CHI}:$ não!

2222 \%act: CHI abaixa-se e encosta no sofá, de frente para a mãe.

$2223{ }^{*} \mathrm{CHI}:$ <não faz cócega $>[<]$ !

$2224 *$ MOT: $\quad<$ O quê> $[>]$ ?

$2225 *$ OBS: $<0[=!$ ri $]>[<]$.

$2226{ }^{*} \mathrm{CHI}$ : não faz cócegas porque <eu> [///] o <Chick_Hicks> [?] xx joga sujo!

2227 \%act: CHI sai correndo em direção ao outro canto da sala e fica olhando para a mãe.

$2228{ }^{*} \mathrm{CHI}$ : ele bate no out(r)o carro!

2229 \%com: CHI refere-se ao fato de que o Chick Hicks trapaceia e bate nos outros carros no filme "Carros".

2230 *MOT: e o que que tem a ver isso com a minha cócega em você?

$2231{ }^{*} \mathrm{CHI}$ : é ele corre assim e vai!

2232 \%act: CHI sai correndo para o outro lado da sala e se joga no sofá, ao lado da mãe.

2233 *MOT: ele corre assim e bate?

2234 * $\mathrm{CHI}$ : e bate no o(u)tro ca:rro!

2235 \%act: $\mathrm{CHI}$ dá um tapa na perna de MOT.

2236 *MOT: mas não bate em mim!

$2237{ }^{*} \mathrm{CHI}$ : não \# porque ele bate no \#\#\# no out(r)o carro!

2238 \%act: CHI volta a correr para o canto da sala.

2239 *MOT: <é: \# eu sei> [>]!

$2240{ }^{*} \mathrm{CHI}:<$ é por isso $>[<]$ !

$2241 *$ OBS: $<0[=!$ ri $]>[>]$.

2242 *MOT: <e o Chick_Hicks vai p(a)r(a) o cantinho do pensamento> $[<]$ ?

$2243{ }^{*} \mathrm{CHI}$ : é \# porque eu vo(u) coloca(r) ele!

2244 \%act: $\mathrm{CHI}$ vai até o centro da sala, onde está a caixa de brinquedo, e pega o carrinho Chick Hicks do chão e volta para o 


\author{
canto da sala com o carrinho. \\ $2245 *$ MOT: <(vo)cê vai por o Chick_Hicks no cantinho do \\ pensamento> $[>]$ ? \\ $2246{ }^{*} \mathrm{CHI}:<$ ele> $[/]$ ele (es)tá aqui. \\ $2247{ }^{*} \mathrm{CHI}$ : ele vai fica(r) no cantinho do pensamento! \\ $2248{ }^{*} \mathrm{CHI}$ : aqui! \\ 2249 \%act: CHI coloca o brinquedo sobre a estante.
}

No episódio acima, os movimentos opositivos mais evidentes são produzidos no contexto de uma espécie de "negociação" entre possibilidade e proibição/interdição de ações esboçadas pelos interlocutores: (G.) "bater" versus "não bater" na mãe; (mãe) "fazer" versus "não fazer" cócegas em G. (2218-2227). A ambiguidade de sentido surge no contexto dessa mesma negociação, quando G. aparentemente tenta justificar o pedido à mãe de que não Ihe faça cócegas (2226) "porque <eu> [///] o <Chick_Hicks> [?] xx joga sujo!" e se afasta correndo (2227). Verifica-se, dessa forma, um contra-argumento de CHI (linha 2223) com uma justificativa (linha 2226). A produção do "porque", em 2226, gera, na mãe, um efeito de sentido/expectativa de justificação para o pedido de G., a partir, talvez, da atribuição de um suposto "querer-dizer" à criança. Essa expectativa é, entretanto, surpreendida pelo conteúdo produzido no acabamento do enunciado, causando uma ruptura no discurso (incongruência). A surpresa gerada (pelo 'porque') a partir da tensa expectativa versus realização enunciativa (acabamento do enunciado) se explicita, no discurso da mãe, pela pergunta que, de imediato, endereça à criança: "e o que que tem a ver isso ("Chick Hicks joga sujo") com a minha cócega em você?" (2230). A ambiguidade não se resolverá, entretanto, na resposta de G., que passa a focar no vilão "Chick Hicks" (2231-2234) e suas ações no filme: correr, bater noutros carros. Um dado curioso surge, entretanto, entre os turnos 2234-2237, nos quais as trocas mãe-criança sugerem, talvez, uma espécie de deslizamento de sentido entre bater 'em outros carros' e bater 'na mãe': (G.) Chick Hicks "bate no o(u)tro ca:rro!"; (mãe) "mas não bate em mim"; (G.) "não \# porque ele bate no \#\#\# no out(r)o carro!". Ir além desse ponto traria, talvez, o risco da superanálise. O risco não impede, por outro lado, que se levantem possibilidades analíticas de entendimento de trocas discursivas particularmente instigantes pela tensão observada entre, por um lado, o nível de elaboração argumentativa implicada na fala de G. (formulação de ponto de vista, esforço de justificação, manejo de oposição; uso de elementos linguísticos adequados à situação discursiva) e, por outro, a ambiguidade que permeia esses mesmos movimentos argumentativos.

\title{
2. 0 humor na fala da criança
}

A questão do humor na fala da criança, como dissemos, vem sendo investigada há algum tempo, devido à sua comprovada importância para o desenvolvimento de competências linguageiras e de aprendizagem (BARIAUD, 1983; AIMARD, 1988; DEL RÉ, 2011; DEL RÉ; 
MORGENSTERN, 2009; DEL RÉ, 2008; DEL RÉ; MORGENSTERN; DODANE, 2015; DEL RÉ et al., 2017). Nesses estudos, o riso, como uma das manifestações do humor, possui papel importante na socialização linguageira, além de poder gerar empatia, um ingrediente importante no processo de aquisição/aprendizagem de línguas (BAKHTIN, 1997).

Nesse viés, podemos definir o humor como fenômeno efetivamente social, ligado às situações afetivas e emotivas, que vão além do apenas fazer rir (DEL RÉ; DE SANTIS, 2017).

De modo geral, os trabalhos dedicaram-se a analisar o humor no adulto, buscando verificar nuances que envolvem o conceito de humor, como é o caso do trabalho de Béal e Traverso (2010) e o de Béal e Mulan (2013). Porém, refletindo sobre o humor na fala da criança, notamos que ele não possui o mesmo estatuto do discurso adulto (DEL RÉ et al., 2015), pois a criança ri, muitas vezes, do absurdo, do anormal, do inesperado, de coisas que o adulto não ri - e vice-versa.

No que se refere a essa incongruência (não normal), o que diferencia as crianças dos adultos é que as primeiras respondem a ela de maneira não realista, i.e., diante de um palhaço com dois narizes, por exemplo, elas não vão dizer algo do tipo "isso não é possível", "um palhaço não tem dois narizes" (na realidade), por isso não é engraçado; ao contrário, ele é justamente engraçado por essa razão. (DEL RÉ, 2011, p. 55).

Ao falarmos sobre humor, alguns elementos parecem ser recorrentes na fala da criança e compõem um conjunto de ingredientes indispensáveis para a produção do discurso humorístico verbal:

[...] uma ruptura é reconhecida enquanto tal pelo locutor; esse reconhecimento depende, de alguma forma, de um recuo, de um trabalho metacognitivo que permita ao locutor identificar que haveria um percurso "normal" para o discurso e que ele foi rompido. A partir daí deve haver por parte desse locutor um querer-partilhar (projeto de dizer/intencionalidade) e a verbalização desse querer para o outro/ interlocutor. Finalmente, ao verbalizar, se houver saber partilhado, os dois vão compreender e, no caso do adulto, eventualmente, rir. No caso da criança, acreditamos que o riso como marca do humor parece ser importante durante o processo de aquisição da linguagem, desta forma ela parece estar sempre presente. (DEL RÉ et al., grifos das autoras, no prelo). 
Desse modo, quatro ingredientes seriam fundamentais: incongruência, recuo, intencionalidade e saber partilhado ${ }^{7}$. Podemos identificar esses ingredientes na fala de S., que faz uso de enunciados humorísticos desde muito pequena.

Vários enunciados humorísticos de S. emergem em situações engraçadas para a família da criança (contexto de sua microcultura). Verificamos esse fato, por exemplo, quando o avô (aniversariante do dia) falava ao telefone com sua filha que mora na Itália (em italiano); S., que também está na sala, ao ver o avô falando ao telefone, deseja falar também (ela a chama de tia) e, ao chegar ao telefone, diz uma expressão inventada em italiano pelo avô para ela (ele diz a palavra especialmente quando ela faz alguma "arte": "mannagia puzzolenta", algo como "ai ai ai, você está aprontando!"). Todos na sala (mãe, observadora/ tia, avô) riem. Após isso, S. volta várias vezes ao telefone, diz o mesmo enunciado e sai de perto. Essa situação, que funciona como algo engraçado para a família, faz com que S. a repita várias vezes. Há, portanto, uma incongruência, gerada pela palavra proferida pela criança, e, também, podemos dizer que há a intencionalidade (especialmente a partir da segunda vez que S. volta para o telefone) por parte da criança, uma vez que ela percebe o efeito que a expressão causa nos interlocutores ao seu redor. Não podemos afirmar que S. teria tido inicialmente o objetivo de provocar esse humor, ou ainda que houve de antemão um distanciamento inicial em relação à situação, mas, ao ver o que a expressão provoca - a ruptura, seguida de riso -, algo desperta em S., o recuo, o reconhecimento de uma situação.

\section{A questão da incongruência e sua relação com o humor e a argumentação}

Na literatura sobre o humor, ressalta-se a importância dos mecanismos desencadeadores do fenômeno humorístico, especialmente da incongruência, da ruptura, daquilo que é surpreendente no diálogo. No entanto, as especificidades dessas incongruências ainda não foram descritas, seja para se pensar o discurso humorístico, seja o argumentativo. Ao que tudo indica, o contra-argumento dado pela criança, no discurso argumentativo, parece constituir uma forma de incongruência que, em alguns casos, produz humor. Mas por que há incongruências no discurso argumentativo que nos fazem rir e outras não?

Baseados em discussões empreendidas com os membros do grupo RIHA e NALingua, em reuniões realizadas tanto na França quanto no Brasil, a noção de incongruência, como

7 Para entender o humor é preciso, criar um recuo, uma distância em relação ao fato, uma habilidade cognitiva que pode ser identificada no discurso pela troca de olhares, gestos. Esses mesmos sinais podem mostrar igualmente um "querer-dizer", uma "intenção discursiva" de divertir o outro (o interlocutor) e a si mesmo, concebida na relação entre os interlocutores, algo que é interpretado pelo outro na relação dialógica. Mas tudo isso só será possível se o conhecimento permitir que o falante e seu interlocutor observem e compreendam as mesmas incongruências (conhecimento compartilhado) (DEL RÉ et al., no prelo). 
um dos ingredientes do humor (infantil), tornou-se ponto central para compreendermos as questões humorísticas e, acreditamos, a argumentação.

Tomamos a incongruência como uma discordância na ordem habitual das palavras ou das coisas, associada ao que podemos chamar de adesão afetiva que "ocasiona uma divergência (em oposição à convergência) ou uma irrupção no encadeamento discursivo" [...] ligada à ideia do estranho, do inesperado, do insólito, do anormal (ou da anormalidade) e da surpresa (DEL RÉ, 2011, p. 107). O resultado dessa surpresa, desse inesperado, é o surgimento do riso ou do sorriso, em uma situação que pode levar ao humor. Para podermos rir, é preciso um "distanciamento, uma distância em relação ao alvo do riso" (DEL RÉ, 2011, p. 108).

$\mathrm{Na}$ argumentação, podemos pensar que essa ruptura está relacionada ao contraargumento, pois, ao sermos confrontados discursivamente com perspectivas contrárias, necessitamos rever nosso enunciado, nosso intuito discursivo, para, então, produzirmos argumentos para convencer nosso interlocutor de nosso querer dizer. Há, portanto, um distanciamento e um repensar sobre o que foi dito, uma ruptura que faz rever nosso próprio dizer. Do mesmo modo, no discurso humorístico, a incongruência aparece como ingrediente essencial, tanto para a compreensão quanto para a produção do humor, sendo gerado a partir de um recuo para a compreensão do todo discursivo para, então, gerar no outro o riso, a partir de uma produção enunciativa intencional de humor.

Essas questões são observadas na criança ainda pequena, como podemos verificar nos dados de S., nos quais se observam as primeiras produções por volta dos dois anos de idade (obviamente, não equiparáveis às produções dos adultos, devido às suas especificidades). Aos quatro anos, por exemplo, S. ${ }^{8}$ está em seu quarto com a observadora, mostrando seus livros. A criança pede que a observadora leia o nome de um dos livros. Ela, então, lê "Faculdade de Filosofia". Sofia pede que ela repita 3 vezes o nome. Na terceira vez, Sofia diz "Sofia?" e olha (desconfiada e rindo) para a observadora, que ri, pois percebe que ela entendia Sofia ao invés de filosofia. S., então, pergunta se a observadora havia dito o seu nome e ri. Em seguida, zombando da observadora, diz, fingindo ler o livro e rindo: "é assim, filo, saco, Alessandra!". A observadora percebe a brincadeira, mas a repreende. Nesta situação, percebe-se uma situação de humor em que a criança faz uso da ironia, com um distanciamento discursivo, em que busca um novo sentido para a palavra com o nome da observadora. Além disso, há intencionalidade de S. em reverter a brincadeira, jogando com o nome da observadora, e uma incongruência para a criança, uma vez que ela pensa que a observadora está brincando com o nome dela (S.).

8 Devido à natureza do dado, que traz elementos de seu nome, optamos por colocar o primeiro nome de $\mathrm{CHI}$, preservando, porém, a identidade e o nome completo da criança. 
Do mesmo modo, podemos perceber argumentação nesses enunciados de S., que, acreditando ser uma brincadeira com ela, com seu nome, uma vez que essas situações são recorrentes na família da criança - não temos como saber se ela identificou que se tratava de uma ironia o enunciado da observadora (ao ler Filo - Sofia) -, traz um novo enunciado à tona (é assim, Filo, saco, Alessandra!). Nota-se que a criança utiliza esse enunciado como um contra-argumento à fala da interlocutora; essa situação de oposição da fala de S. é compreendida pela observadora, que tenta, no decorrer do episódio, mostrar a ela, apontando para o livro, que era, de fato, aquele nome que estava escrito e que ela não fez de propósito.

Outra incongruência, que gera tanto humor quanto argumentação, encontramos em G., que, no episódio abaixo, está com 3;6 anos (DEL RÉ et al., 2015), guardando os seus carrinhos na sala com o pai. Quando o pai lhe solicita que guarde todos os carrinhos de corrida, G. responde, girando uma das mãos:

G: o quê, o quê, o quê, o quê, o quê, o quê rapaz? Veja se tem um carrinho aqui, de corrida?

Pai: Não, não tem. (todos riem, menos G.).

O riso nessa situação é gerado por uma conjunção de fatores e que nos faz olhar para a dialogia (BAKHTIN, 2007) desse episódio. Em sessões anteriores, é possível ver o pai de G., em várias situações de interação e de saber partilhado com a criança, fazer uso do mesmo enunciado ("o quê, o quê, o quê, o quê, o quê, o quê rapaz?"), com mudança no tom de voz. Essa situação discursiva traz a ironia da fala do pai como um componente, já que o pai sempre utiliza esse enunciado em oposição às ideias ou ações de G. (quando ele faz algo que o pai não gosta, por exemplo). Assim, o fato de G. utilizar esse enunciado em um outro contexto discursivo gera incongruência no discurso, que possibilita aos interlocutores recuperarem esses já ditos e, nesse recuo, possibilita eles rirem da estratégia da criança. Essa estratégia pode ser, também, observada no contra-argumento de G. ao ser solicitado que ele guarde os carrinhos (com o enunciado "o quê, o quê, o quê, o quê, o quê, o quê rapaz?"), justificando seu argumento com "Veja se tem um carrinho aqui, de corrida?". A resposta do pai é dada no enunciado seguinte, com a aceitação total da oposição de G. Esse contra-argumento, portanto, traz ruptura para o diálogo, fazendo com que o pai reformule seu ponto de vista inicial.

\section{Considerações e discussões sobre o tema}

Nossas primeiras observações demonstram que as crianças utilizam precocemente estratégias linguísticas, tanto para defender seu ponto de vista quanto para escapar da repreensão de seus pais, e, muitas vezes, elas as fazem utilizando o humor (VIEIRA, 2015). Ainda que não sigam normas do discurso do adulto, o fato de as crianças se 
posicionarem diante do discurso do outro indica que não somente começam a compreender a complexidade do processo de comunicação verbal, fazendo uso dos jáditos para defender seu ponto de vista, como também que estão em pleno processo de constituição de sua subjetividade (FRANÇOIS, 2009). Acreditamos, pois, que, quando a criança utiliza estratégias fazendo uso do humor, podemos verificar um indício realmente importante do desenvolvimento linguístico-discursivo (e de cognição) da criança, uma vez que ela passa a entender mecanismos essenciais para convencer o outro, a partir da empatia, por exemplo.

Ao olharmos para os dados aqui analisados, verificamos distintas situações discursivas nas quais emergem, da fala da criança, discursos argumentativos e humorísticos. A nosso ver, a argumentação tem papel essencial na aquisição/aprendizagem do conhecimento, uma vez que, ao ser confrontada, a criança reformula ou reflete sobre seus argumentos para conseguir convencer o outro. Importância similar tem o humor na fala da criança, principalmente no desenvolvimento e socialização infantis, que é um dos elementos, acreditamos, responsáveis por avanços cognitivos no desenvolvimento (DEL RÉ, 2011; DEL RÉ, 2003b).

Nesse sentido, compreender como emergem e funcionam esses elementos na linguagem da criança pode auxiliar a desvendar os mistérios da rapidez e agilidade com que as crianças aprendem e de que maneira esses elementos auxiliam, de fato, no desenvolvimento da linguagem. Outrossim, ao compreendermos questões que envolvem o universo infantil, especialmente no que diz respeito ao discurso humorístico e argumentativo, poderemos agir e orientar melhor o próprio setor da Educação, refletindo sobre como o conhecimento vem sendo transmitido às crianças e sobre as consequências do uso da argumentação e do humor no processo de ensino/aprendizagem do conhecimento e na vida adulta dessas crianças.

O que podemos observar a partir dos dados é que a incongruência, como um elemento de surpresa e ruptura, pode gerar no discurso situações que podem estar voltadas para a defesa de pontos de vista (com ou sem justificativa), ou para enunciados mais humorísticos ou para ambos. Isso pode ser recuperado nos dados analisados, nos quais temos a criança defendendo um ponto de vista para a mãe - que foi contrariado (Episódio 1) - ou a criança brincando com a situação discursiva e com a língua em interação (Episódio 2) ou, ainda, situações que fornecem um outro ponto de vista (no caso, com o uso da ironia) a partir de enunciados que geram humor (como os episódios 3 e 4).

O que notamos, a partir dessas discussões e análises, é que a incongruência é um elemento essencial para a emergência desses discursos; porém, os tipos de incongruência talvez tenham especificidades e objetivos distintos (e podem ser muitos), algo que ainda deve ser investigado. 
$\mathrm{Na}$ continuidade da pesquisa, pretende-se, igualmente, acrescentar a importância desses estudos e dessas questões na aquisição de uma língua de sinais (no caso do Brasil, a Libras), contribuindo para mostrar efetivamente que tanto as crianças $\operatorname{CODAS}^{9}$, expostas à LIBRAS, quanto as ouvintes possuem processos de desenvolvimento da linguagem análogos e que a argumentação e o humor, ainda que não apareçam sempre juntos, contribuem para o desenvolvimento da linguagem da criança e estão, de algum modo, ligados às questões sociais e culturais. Desse modo, a partir de dados distintos, poderemos verificar quais tipos de incongruência são passíveis de serem identificados no discurso dessas crianças.

\section{REFERÊNCIAS}

AIMARD, P. Les bébés de l'humour. Liège-Bruxelles: Pierre Mardaga, 1988.

BAKHTIN, M. Os gêneros do discurso. In: BAKHTIN, M. Estética da criação verbal. Tradução Maria Ermantina Galvão Gomes Pereira. São Paulo: Martins Fontes, 1997.

BAKHTIN/VOLOSHINOV. Discurso na vida e discurso na arte. 1926. Tradução Inédita de Cristovão Tezza do artigo "Discourse in Life and Discourse in Art", publicado como apêndice in: VOLOSHINOV, V. N. Freudianism: a marxist critique. New York: Academic Press, 1976.

BAKHTIN/VOLOCHÍNOV. Marxismo e filosofia da linguagem. Tradução Michel Lahud e Yara F. Vieira. 7. ed. São Paulo: Hucitec, 1995.

BARIAUD, F. La genèse de l'humour chez l'enfant. Paris: Presses Universitaires de France, 1983.

BÉAL, C.; TRAVERSO V. Hello, we're outrageously punctual: front door rituals between friends in France and Australia, Journal of French Language Studies, v. 20-1, p. 17-29, 2010.

BÉAL, C.; MULLAN, K. Issues in conversational humour from a cross-cultural perspective: comparing French and Australian corpora. In: BÉAL, C.; MULLAN, K.; PEETERS, B. (ed.). Cross-culturally Speaking, Speaking Cross-culturally. Cambridge: Cambridge Scholar Press, 2013.

DEL RÉ, A. A criança e a magia da linguagem: um estudo sobre o discurso humorístico. São Paulo: Cultura Acadêmica, 2011.

9 CODA é a sigla para "Children of Deaf Adults". São denominadas CODAS as crianças ouvintes, filhas de pais surdos. 
DEL RÉ, A. Aquisição da linguagem: uma abordagem psicolinguística. São Paulo: Contexto, 2006.

DEL RÉ, A. Explicação e humor na linguagem da criança. In: FERNANDES, S. D. Aquisição da Linguagem: conceito, definição e explicação na criança. Araraquara: Cultura Acadêmica - FCL/UNESP, 2003a. (Trilhas Linguísticas, 4)

DEL RÉ, A. L'explication et l'humour chez le jeune enfant. La linguistique, Paris, v. 39, p. 7591, 2003b.

DEL RÉ, A.; DE PAULA, L.; MENDONÇA, M. A linguagem da criança: um olhar bakhtiniano. São Paulo: Contexto, 2014a.

DEL RÉ, A.; DE PAULA, L.; MENDONÇA, M. Explorando o discurso da criança. São Paulo: Contexto, 2014b.

DEL RÉ, A.; HILÁRIO, R. N.; MOGNO, A. S. Aquisição da linguagem: a singularidade, a recorrência, as generalizações In: DEL RÉ, A.; DE PAULA, L.; MENDONÇA, M. A linguagem da criança: um olhar bakhtiniano. v. 1. São Paulo Contexto, 2014. p. 137-154.

DEL RÉ, A.; HILÁRIO, R. N.; VIEIRA, A. J. Subjetividade, individualidade e singularidade na criança: um sujeito que se constitui socialmente. Bakhtiniana: Revista de Estudos do Discurso, v. 7, p. 57-74, 2012.

DEL RÉ, A.; MORGENSTERN, A. To laugh or not to laugh: that is the question, in IADA 2009 - Polyphony and Intertextuality in Dialogue. Barcelona: University of Münster, v. 2, p. 41-54, 2009.

DEL RÉ, A.; MORGENSTERN, A.; DODANE, C.; QUIMELLO, H. Diversão partilhada, humor e ironia: um estudo sobre a produção de enunciados por uma criança brasileira. In: DEL RÉ, A.; PAULA, L. de; MENDONÇA, M. (ed.). Explorando o discurso da criança. São Paulo: Contexto, 2014.

DEL RE, A.; DODANE, C.; CAVALCANTE, M. C. B.; MASSINI-CAGLIARI, G. Discurso, prosódia e multimodalidade na produção humorística de uma criança monolíngue. In: SILVA, C. L. da; DEL RÉ, A.; CAVALCANTE, M. A criança na/com a linguagem: saberes em contraponto. v. 1. Porto Alegre: Instituto de Letras, UFRGS, 2017.

DEL RÉ, A.; MORGENSTERN, A.; DODANE, C. Enunciados humorísticos infantis em foco: implicações pragmáticas, cognitivas e sociais. Revista Alfal, no prelo. 
DODANE, C.; JEREMI SAUVAGE, F. H.; BARKAT-DEFRADAS, M.; DEL RÉ, A. Riso e discurso: do acústico ao contextual. In: DEL RÉ, A.; PAULA, L. de; MENDONÇA, M. (ed.). Explorando o discurso da criança. São Paulo: Contexto, 2014. p. 35-53.

DEL RÉ, A.; HILÁRIO, R. N.; ANTÔNIO RODRIGUES, R. O corpus NALingua e as tecnologias de apoio: a constituição de um banco de dados de fala de crianças no Brasil, Artefactum, v. 13, p. 1-16, 2016.

DEL RE, A.; DODANE, C.; MORGENSTERN, A. De l'amusement partagé à la production de l'humour chez l'enfant. In: FARHAT, M.; LACOSTE, F. (ed.). L'humour dans le bassin méditerranéen: contacts linguistiques et culturels. v. 1. Tunísia: Nouha éditions, 2015. p. 115-139.

DEL RE, A.; DE SANTIS, A. B.. Algumas reflexões sobre a constituição do discurso humorístico infantil: o caso de uma criança bilíngue franco-brasileira. In: BARBOSA, M.; MORAIS, C. F. de; VIDAL, M. E. B. (Org.). Teorias de Linguagens: pesquisa e ensino. Campinas: Mercado de Letras, 2017. p. 109-128.

FRANÇOIS, F. Morale et mise en mots. Paris: L'harmattan, 1994.

FRANÇOIS, F. Essais sur quelques figures de l'orientation: hetetogénéité, mouvements et styles. Paris: Éditions Lambert-Lucas, 2009.

FREUD, S. Os chistes e sua relação com o inconsciente. v. VIII. Tradução Jayme Salomão. In: Edição Standard Brasileira das Obras Completas de Sigmund Freud. Rio de Janeiro: Imago, 1969 [1905].

LEITÃO, S. Auto-argumentação na linguagem da criança: momento crítico na gênese do pensamento reflexivo. In: DEL RÉ, A.; FERNANDES, S. D. (org.). A linguagem da criança: sentido, corpo e discurso. São Paulo: Cultura Acadêmica, Série Trilhas Linguísticas 15, 2008a. p. 35-60.

LEITÃO, S. Beyond narrative: an excursion into argumentation-based relations within the dialogical self. Paper presented at the 8th dialogical self-conference. Cambridge, UK, 26-28, August, 2008b.

LEITÃO, S. Processos de construção do conhecimento: a argumentação em foco. Pro-Posições, Campinas, v. 18, n. 3 [54], p. 75-92, set./dez. 2007 a. 
LEITÃO, S. Argumentação de desenvolvimento do pensamento reflexivo. Psicologia: Reflexão e Crítica, v. 20, n. 3, p. 454-462, 2007b. Disponível em: http://www.scielo.br/pdf/ prc/v20n3/a13v20n3.pdf. Acesso em: 10 jun. 2010.

LEITÃO, S. Analyzing changes in view during argumentation: a quest for method. Forum: Qualitative Social Research, Art 12, v. 2, n. 3, 2001. [não paginado]

LEITÃO, S.; BANKS-LEITE, L. Argumentação na linguagem infantil: algumas abordagens. In: DEL RÉ, A. Aquisição da linguagem: uma abordagem psicolinguística. São Paulo: Contexto, 2006.

LEITÃO, S.; DAMIANOVIC, M. C. (org.). Argumentação na escola: o conhecimento em construção. Campinas: Pontes Editores, 2011.

LEITÃO, S.; FERREIRA, A. P. M. Argumentação infantil: condutas opositivas e antecipação de oposição In: MEIRA, L.; SPINILLO, A. G. (ed.). Psicologia cognitiva: cultura, desenvolvimento e aprendizagem. Recife: Editora Universitária da UFPE, 2006. p. 236-263.

LEITÃO, S.; VIEIRA, A. J. Gênese da oposição na fala da criança. In: SILVA, C. L.; DEL RÉ, A.; CAVALCANTE, M. B. A criança na/com a linguagem: saberes em contraponto. v. 1. Porto Alegre, Instituto de Letras, UFRGS, 2017.

LEYFER, O. T.; FOLSTEIN, S.; BACALMAN, S.; DAVIS, N. O.; DINH, E.; MORGAN, J.; TAGERFLUSBERG, H.; LAINHART, J. E. Comorbidades Psiquiátricas em Crianças com Autismo: Desenvolvimento de Entrevista e Taxa de Transtornos (Comorbid Psychiatric Disorders in Children with Autism: Interview Development and Rates of Disorders). Disponivel em: http://bit.ly/32jbCn8. Acesso em: 10 jun. 2016.

MORGENSTERN, A. Un je en construction: gênese de l'auto-designation chez le juene enfant. Paris: Ophrys, 2006.

SALAZAR-ORVIG, A. Les mouvements du discours: style, référence et dialogue dans des entretiens cliniques. Paris: Harmattan, 1999.

PLATÃO. P. E Euvres complètes. v. 9. Parte 2. Tradução Auguste Diès. Paris: Belles Lettres, 1959.

VIEIRA, A. J. Condutas argumentativas na fala infantil: um olhar sobre a constituição da subjetividade. 2011. Dissertação (Mestrado em Linguística e Língua Portuguesa) Universidade Estadual Paulista "Júlio de Mesquita Filho", Araraquara, 2011. 
VIEIRA, A. J. Argumentação e Explicação na linguagem da criança: diferenças e intersecções em dois estudos de caso. 2015. Tese (Doutorado em Linguística e Língua Portuguesa) Universidade Estadual Paulista "Júlio de Mesquita Filho", Araraquara, 2015.

VIEIRA, A.; LEITÃO, S. Condutas argumentativa e explicativa: o uso de porquês na linguagem infantil. In: DEL RÉ, A.; DE PAULA, L.; MENDONÇA, M. Explorando o discurso da criança. São Paulo: Contexto, 2014. 